\title{
Theoretical and practical aspects in the etiology, diagnostic and treatment in surrounding tissues of the dental implant affections: Peri-implantitis
}

Ilinca Ana LAZAR ${ }^{1}$, Gabriela TANASE ${ }^{1}$, Augustin MIHAI $^{1}$, loana VOINESCU ${ }^{1}$, Viorel PERIEANU ${ }^{1}$, Maria Glencora COSTACHE ${ }^{1}$, Madalina Violeta PERIEANU ${ }^{1}$, Claudia-Camelia BURCEA ${ }^{1}$, Madalina MALITA ${ }^{1}$, Irina Adriana BEURAN ${ }^{1}$, Liliana BURLIBASA ${ }^{2}$, Gabriela IORGULESCU ${ }^{1}$, Narcis MARCOV ${ }^{1}$, Magdalena Natalia DINA ${ }^{1}$, Mihai BURLIBASA ${ }^{1}$, Luminita OANCEA ${ }^{1}$, lleana IONESCU ${ }^{1}$, Elena-Cristina MARCOV ${ }^{1}$

1"Carol Davila" University of Medicine and Pharmacy, Bucharest, Romania

${ }^{2}$ Faculty of Biology, University of Bucharest, Romania

\begin{abstract}
Introduction. Peri-implantitis is a non-specific inflammation, induced or maintained in the host tissues. Peri-implantitis usually presents a succession of specific symptoms, such as: bleeding on palpation, mobility of the dental implant, pain, increased depth of the pockets located around dental implants.

Purpose. Thus, in this material we wanted to carry out a review of the main notions, both theoretical and practical, which characterize the diseases of surrounding tissues of dental implant called peri-implantitis.

Material and method. For this study, we used 31 practitioners from Bucharest who frequently perform implant-prosthetic rehabilitation treatments, based on a questionnaire consisting of 6 questions.

Results and discussions. The doctors included in the study showed that they have a thorough training in the field of implant-prosthetic restorations and of course in the diagnosis and treatment of peri-implantitis.

Conclusions. In-depth knowledge of the notions related to peri-implantitis leads to an early diagnosis, favoring the rapid application of a treatment that prevents the occurrence of subsequent complications.
\end{abstract}

Keywords: peri-implant diseases, implant-prosthetic rehabilitation, oral implantology

\section{INTRODUCTION}

If, more than 2 decades ago, in Romania, both the insertion of dental implants and their prosthetic rehabilitation represented a rather delicate problem among dental specialists, nowadays, these implant- prosthetic rehabilitation procedures have become, and become daily, routine operations, for an increasing number of dentists.

In fact, we refer to a pioneering period in Romanian implantology and, it started shy in Romania, almost immediately after 1990, but became a real trend in 
dental practice, only after 1996, when, a number of extremely important factors, favored the implementation in our country of these techniques (considered revolutionary at that time) for oral rehabilitation, for almost any type of edentation, maxillary and/or mandibular, by inserting dental implants, followed by their subsequent prosthetic rehabilitation by dental practitioners with implant-supported restorations fixed or mobile. Of those factors mentioned above, which have contributed to the emergence in Romania of implant-prosthetic rehabilitation techniques, we must mention:

- the introduction in the educational curricula of the faculties of dentistry in Romania as a study discipline of oral implantology;

- the appearance of postgraduate courses in oral implantology, more or less accessible for dental practitioners in Romania. In our case, it is about that competence in oral implantology that first appeared in Bucharest and which took place in the Central Military Hospital, under the careful coordination of Professor Augustin Mihai, MD, $\mathrm{PhD}$;

- introducing on the Romanian dental market both a competitive equipment and instruments, but also some specific materials for the implant-prosthetic rehabilitation of a much newer generation.

But, at the level of 2019, the implant-prosthetic rehabilitation has become, with the increasing number of dental practitioners, a routine in the specialized dental offices. Basically, more and more dentists are starting from the idea that, the rehabilitation of any type of edentation can be done extremely quickly and professionally, by inserting dental implants and their subsequent prosthetic restoration. And, this aspect has become almost a normality among the dental practitioners in Romania, considering the much greater benefits that they have from the implant-prosthetic rehabilitation treatments, compared to the traditional general dentistry treatments.

Unfortunately, implant-prosthetic rehabilitation is not really a treatment with absolute success. As in any medical act, a series of failures and complications can occur, which can lead immediately or in time to some quite serious failures for both the patient and the medical team. Thus, even in the case of implant-prosthetic rehabilitation, a multitude of failures may occur, due to complications occurring either during the insertion of dental implants, or after surgical step, immediately and/or late. Such a complication that may occur during an implant-prosthetic rehabilitation is represented by peri-implantitis: we actually talk about a late complication of the implant treatment, it is of microbial cause, and if it is not treated in time and/or properly, it can even lead at the loss of the dental implant.

\section{GENERAL DATA}

In almost any medical act, and especially in the acts with a pronounced surgical component, as are some medical acts specific to oral implantology, accidents can occur, materialized both by failures and complications. A classification of these accidents and complications can be stated as follows (1):

a. accidents (intraoperative incidents);

b. complications arising during the period of osseointegration;

c. accidents that may occur when mounting the prosthetic abutment and when fixing or cementing the prosthetic superstructure;

d. late complications.

Thus, peri-implantitis, conditions localized in the tissues around dental implant that we have addressed in this material, are part of the of late complications category, which we encounter in oral implantology (1).

But what peri-implantitis are actually?

Specifically, the "peri-implantitis" term was introduced by Mombelli et al., in a study on the microbial flora around dental implants, with and without bone loss, being defined as follows: "Peri-implantitis can be considered a localized infection, which has many aspects in common with chronic periodontitis" $(2,3)$. However, peri-implant disease, as defined in the first Workshop of Periodontology - Ittingen, Switzerland, since 1993, differ in two stages $(3,4)$ :

1. Peri-implantary mucositis: is a reversible inflammatory reaction of the mucosa adjacent to a dental implant;

2. Peri-implantitis: it is an inflammatory process that affects the tissues around an osseointegrated dental implant that is functionally loaded and causes loss of supporting bone tissue $(3,4)$.

However, the definitions associated with peri-implantitis did not stop here. Thus, during the 6th Workshop of Periodontology, some minor modifications of these definitions were made, namely: the terms "reversible" / "irreversible" were removed, it was specified that peri-implantitis is of an infectious nature and it was pointed out that: "peri-implant mucositis is an inflammatory lesion, which affects the mucosa around the dental implant, while peri-implantitis also affects the supporting bone tissue" $(3,5,6)$.

In the specialty literature, several risk factors in the production of peri-implantitis are highlighted, but which are also associated with the presence of periodontal diseases $(3,6)$. The risk factors in the production of peri-implantitis are $(3,6,7)$ : 
- Smoking. The risk of peri-implantitis disease is double in smokers, compared to non-smokers (3);

- The history of periodontal disease. Patients with periodontal disease treated with dental implants have an increased risk of developing peri-implantitis. Specifically, untreated periodontal disease is a risk factor in the evolution of treatment with dental implants (3);

- Poor oral hygiene. Most clinical studies in the specialty literature associate poor oral hygiene with the appearance of peri-implantitis;

- Microbial agents. Studies using electron microscopy and techniques based on anaerobic bacterial cultures have shown that microorganisms associated with healthy periodontal tissues or with mild gingival inflammation are similar to those found in clinically healthy sulcus around dental implant, the treatment failure it is largely determined by pathogenic microorganisms similar to those involved in adult periodontitis (3);

- Surface of dental implants. There is a direct relationship between the surface roughness of dental implants used and the degree of microbial colonization above and below gingival margin (7).

But, when we discuss about the diagnosis of peri-implantitis, this is, in most cases, similar to periodontal disorders and is characterized by $(3,7)$ :

- The presence of vertical destruction of the alveolar bone;

- Formation of pockets around implants;

- Edematous tissues;

- Mobility of the implant;

- Bleeding and/or suppuration at slight palpation, etc.

However, in order to establish a correct diagnosis in the case of peri-implantitis, both the use of high quality imaging examinations (conventional radiography, panoramic radiography, digital radiography, etc.) and a firm and relevant interpretation of them are mandatory.

\section{PURPOSE}

Starting from these aspects presented in the General Data part, in the specialized literature, some general objectives have been stated, regarding the treatment of peri-implantitis, as follows $(3,7)$ :

- Removal and/or modification of the microbial plaque from the peri-implant sulcus;

- Decontamination and conditioning of the surfaces of dental implants;

- Correction and / or elimination of sites, which cannot be properly cleaned;
- Establishing an efficient control protocol of the microbial plaque;

- Bone reintegration of dental implants.

Thus, the enunciation of these general principles of treatment, will constitute the first steps in the particularization of a specific treatment, for each case of peri-implantitis (11-18).

But we, the authors, consider that these previously presented notions, regarding peri-implantitis, must be well known and well understood by all dental practitioners, especially those who perform mainly implant-prosthetic rehabilitation treatments, aspect that actually constitutes, and the purpose of this report (19-24).

\section{MATERIAL AND METHOD}

In carrying out this study, we used a questionnaire, which presented a number of advantages, such as (810):

- The speed and convenience of obtaining guidance information for prospecting purposes;

- Trends of opinion;

- Sincerity of the answers, due to anonymity and confidentiality;

- Capture the influence of a facilitating and disruptive factor, before the effects are factually visible.

Specifically, a questionnaire consisting of 6 items was used. It was applied, subjected to anonymity, to a number of 31 dental practitioners from the private system, from the Bucharest, who frequently perform specialized implant-prosthetic rehabilitation treatments, but insisting mainly on the surgical component of this type of treatment, namely, on the insertion of dental implants. Dental practitioner's age ranged from 30 to 55 years, and gender distribution was as follows: 17 of the subjects were male (54.84\%), while 14 subjects were female (45.16\%) (Fig. 1).

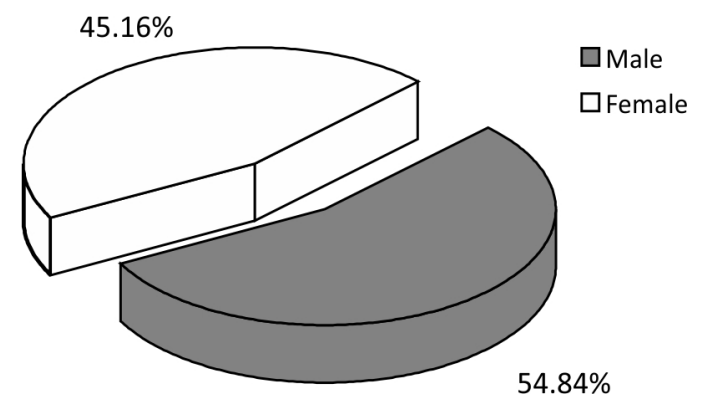

FIGURE 1. Gender distribution of subjects included in study

Questionnaire

1. Before performing implant-prosthetic rehabilitation treatments: 
a. You have taken postgraduate training courses such as a competence in implantology and/or have taken other types of theoretical and practical training courses?

b. Did you learn from other qualified persons?

c. Did you learn strictly based on an individual study?

\section{Correct answer: $\boldsymbol{a}$.}

2. Accidents and complications in oral implantology can be systematized as follows?

a. Accidents (intraoperative incidents), but also complications that occurred during the osseointegration period;

b. Accidents that may occur when mounting the prosthetic abutment and fixing or cementing the prosthetic superstructure, but also late complications;

c. Accidents of antagonist teeth / accidents of the soft tissues.

\section{Correct answers: $\boldsymbol{a}, \boldsymbol{b}$.}

3. Peri-implantitis is a localized infection, which has many aspects in common with chronic periodontitis, and is different in several aspects as?

a. Peri-implantary mucositis, which is an inflammatory reaction of the mucosa adjacent to a dental implant;

b. Peri-implantitis, which is an inflammatory process, which affects the tissues around an osseointegrated prosthetically functional loaded dental implant, and which causes the loss of supporting bone;

c. Periodontitis, which is a chronic irreversible disease, with the presence of gingival inflammation located in areas in which there was a pathological attachment loss of fibers from the periodontal ligament to cement, with the apical migration of the junctional epithelium and a bone loss that can be radiologically detected?

\section{Correct answers: $\boldsymbol{a}, \boldsymbol{b}$.}

4. The risk factors in the production of peri-implantitis are?

a. Smoking and history of periodontal disease;

b. Poor oral hygiene and microbial agents;

c. Surface of dental implants;

d. Polluting and climatic factors.

\section{Correct answers: $a, b, c$.}

5. The diagnosis of peri-implantitis is similar to periodontal disease and includes the following aspects?

a. Presence of vertical destruction of the alveolar bone and formation of peri-implant pockets;

b. Edematous tissues, bleeding and/or suppuration at slight palpation, implant mobility;

c. A radiologic examination is also required;

d. Removal from the first moment of the dental implant?

\section{Correct answers: $a, b, c$.}

6. The classic treatment principles of peri-implantitis are the following?

a. Removal and/or modification of the microbial plaque from the peri-implant sulcus;

b. Decontamination and conditioning of dental implants surfaces;

c. Correction and/or removal of areas that cannot be properly cleaned;

d. Establishing an efficient control protocol of the microbial plaque;

e. Bone reintegration of the dental implant;

f. Emergency removal of the entire implant-supported prosthetic restoration.

Correct answers: $a, b, c, d, e$.

\section{RESULTS}

The first thing we observe, and which gives greater value to the study, is that all participants in this study have attended and graduated in different forms specialized courses in oral implantology. This shows the interest of those involved in the study for practicing correctly with solid knowledge in order to obtain the best results.

About the accidents and complications existing in the oral implantology, 22 doctors (representing 70.97\%) answered correctly, while only 9 doctors included besides the correct variants and the answer variant c (Fig. 2).

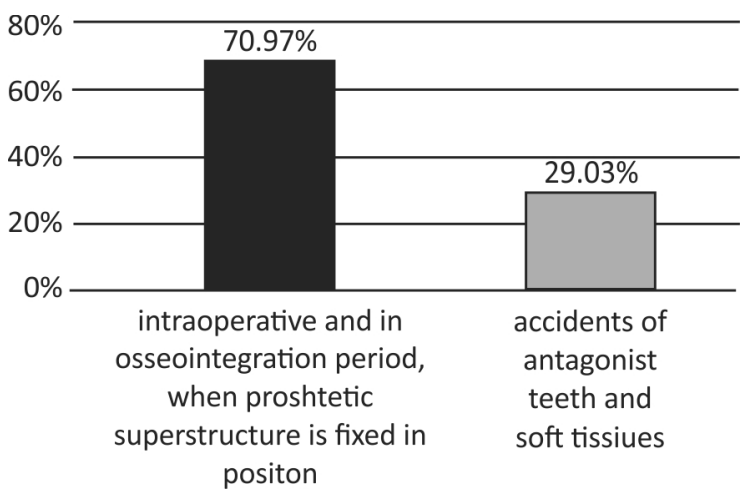

FIGURE 2. Systematization of accidents and complications in oral implantology

The differences between chronic periodontitis and peri-implantitis were correctly reported by the majority of study participants (29 representing 93.55\%), while only 2 participants (representing 6.45\%) answered incorrectly (Fig. 3). 


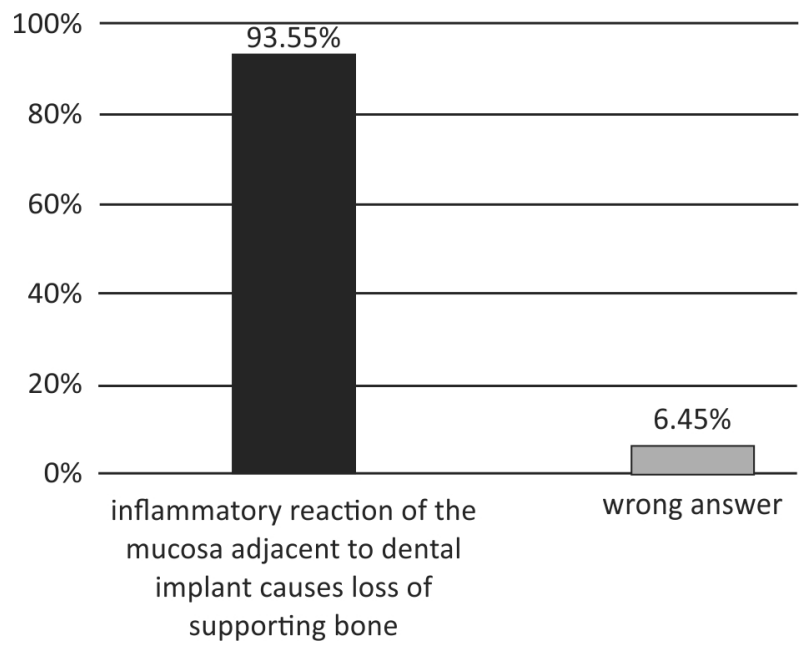

FIGURE 3. Differences between chronic periodontitis and periimplantitis

Regarding the risk factors in the production of peri-implantitis, only 12 respondents answered incorrectly (representing $38.71 \%$ ), while the rest of 19 respondents answered correctly, namely smoking, periodontal disease in history, poor oral hygiene and the surface of the implants (Fig. 4).

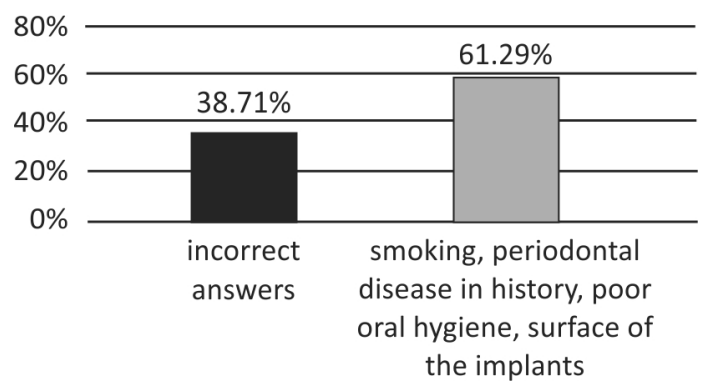

FIGURE 4. Risk factors in the production of peri-implantitis

Concerning the elements that establish the diagnosis of peri-implantitis all participants in the study answered correctly.

Also to the last question about the classical principles in the treatment of peri-implantitis all the practitioners included in the study answered correctly. This shows the increased level of professional training of those who participated in this study.

\section{DISCUSSION}

With the widespread use of dental implants, several aspects began to be analyzed in addition to the surgical and osseointegration stages. Just as the tooth is fixed in the bone through the root and the dental crown is visible in the oral cavity, so the implant is fixed in the bone and the prosthetic work fixed on the implant is visible in the oral cavity.

The use of prosthetic works on implants over time has led to the detection, diagnosis and subsequent de- velopment of treatment schemes for peri-implantitis. In a review published by Smeets et al. in 2014 are analyzed based on the literature: definition, etiology, prevention and treatment of peri-implantitis (25). In 2018, Schwarz et al. conducted an exhaustive narrative review, and if the first study focused more on the treatment side, Schwarz et al. they tried to shed light on several aspects of peri-implantitis. They analyzed as follows: current definition, conversion from peri-implant mucositis to peri-implantitis, onset and pattern of disease progression, characteristics of peri-implantitis, risk factors / indicators for peri-implantitis, progressive crestal bone loss in the absence of soft tissue inflammation (26). The most widely accepted definition is the one stated in "The Consensus Report of Workgroup 4 of the 2017 World Workshop on the Classification of Periodontal and Peri-Implant Diseases and Conditions: peri-implantitis is an inflammatory process from a microbial origin that causes bone loss and if not treated could lead to the loss of the implant-supported restoration (27). In 2019, Monje et al. conducted another review to highlight the correlation between peri-implantitis, dental plaque and predisposing factors (28).

For these reasons, several important study directions are outlined, namely: establishing the diagnosis, correlating with risk factors, prevention and treatment of peri-implantitis.

While the aforementioned studies describe in detail the elements on the basis of which the diagnosis of peri-implantitis is established, there are numerous other studies that cover the rest of the research area.

In a study published in 2015, Jepsen et al. described the management of peri-implant mucositis in order to prevent the occurrence of peri-implantitis (29).

Regarding the risk factors, Stacchi et al. conducted a review connected to the role of the history of periodontal disease and smoking habits for peri-implantitis. The conclusion they reached is that the history of periodontal disease could be a risk factor while for smoking there is not enough data to assess its role in the appearance of peri-implantitis (30). Analyzing the implant-based factors as possible risk factors for peri-implantitis, Zandim-Barcelos et al. concluded that there is a connection between the occurrence of peri-implantitis and the implant-based factors, but for a better understanding further evidences are require (31). Also Ahn et al. in their study showed that there is a statistically significant link between smoking and peri-implantitis. Another significant factor was prosthetic splinting (32).

Regarding the treatment, one thing is clear, once the condition is detected, it is necessary to intervene to remove the inflammatory factors and restore the affected tissues. Whether a preventive therapy of 
maintenance is approached, as described in the study conducted by Rösing el al. (33), or more aggressive therapy when the condition is detected late or as a result of material defects as described by Wang et al. (34).

As can be seen, there are recent studies (20142019), which means that it is a constantly evolving condition and its understanding and treatment are not complete.

For this reason, the knowledge of the elements that lead to the diagnosis of peri-implantitis, as well as the elements that help the differential diagnosis of marginal periodontitis, as we showed in this article, plays an important role in the early detection of this condition. In the same way, the risk factors that favor the appearance of peri-implantitis must be known, in this sense being many studies that highlighted a series of factors involved in the appearance of peri-implantitis such as: smoking, periodontal disease in history, poor oral hygiene, surface of the implants.

What is more important besides the theory part, specific to researchers and those from university centers, is the knowledge and understanding of these aspects by doctors who perform implant-prosthetic treatments in the private health network, which we tried to highlight by this study.

The subjects from this study were between the ages of 30 and 55, which denotes an extremely interesting thing, in this age range, this type of maneuvers with surgical component (insertion of dental implants), has such an excellent accuracy.

It should be noted that compared to other surgical specialties among practitioners dealing with the surgical insertion of dental implants we find both women and men in a portion that tends to be equalized.

All the subjects involved in the study have followed postgraduate training courses as implantology competence and/or other types of theoretical and practical training courses, which is very important, because they wanted the acquisition of theoretical and practical knowledge in the field of oral implantology, to be realized by the teaching by specialized personnel and with a lot of didactic experience. At the same time, the dental practitioners involved in the study have stated that obtaining a diploma for graduating such training courses gives them a legal status in approaching the implant-prosthetic rehabilitation treatments.

\section{CONCLUSIONS}

More than 2/3 of the dental practitioners (about $71 \%$ ) who chose to answer the questions are aware of the risks, accidents and complications, following the implant-prosthetic rehabilitation treatments.

Most of the dental practitioners involved in the study (about 97\%), make a clear and categorical distinction between peri-implantitis, peri-mucositis and periodontal disease.

Almost $2 / 3$ of the subjects involved in the study (approximately 62\%) have a strong knowledge regarding the risk factors incriminated in the production of peri-implantitis, while $1 / 3$ of the dental practitioners who have chosen to answer the questionnaire do some little confusion about these details.

Both regarding the diagnosis of peri-implantitis and the classical principles of treatment of these conditions, all the practitioners involved in the study have proven that they know very well both the theoretical and practical notions related to these vital aspects in the survival of a dental implant on the arch.

\section{Acknowledgement}

In this article, all the authors have equal contribution with the first author.

Conflict of interest: none declared Financial support: none declared

\section{REFERENCES}

1. Gănuță N, Bucur A. Gănuță A. Tratat de implantologie orală. Editura Național, București, 1997.

2. Mombelli A, Van Oosten MA, Schurch E Jr. et al. The microbiota associated with successful or failing osseointegrated titanium implants. Oral Microbiol Immunol. 1987;2:145-151.

3. Cristache CM. Periimplantita: Factori de risc, etiologie, patogenie, prevenție și tratament. În: Burlibașa M, Cristache CM, Tănase $\mathrm{G}$ (coord.). Progrese în medicina dentară, Vol. 2. Editura Ars Docendi, București, 2011, pp. 130-168.
4. Albrektsson T. Isidor F. Consensus report of session IV. In: Lang NP, Karring T (eds.). Proceedings of the 1st European Workshop on Periodontology. Berlin: Quintessence, 1994, pp. 365-369.

5. Lindhe, J, Meyle J. Peri-implant diseases: Consensus Report of the sixth European Workshop on Periodontology. J Clin Periodontol. 2008;35(8):282-285.

6. Bergström J. Periodontitis and smoking: An evidence-based appraisal. J Evid Based Dent Pract. 2006;6:33-41.

7. Lazăr L, Forna NC. Periimplantitele diagnostic și tratament. Romanian Journal of Medical and Dental Education. 2016;5(1):62-71.

8. Gagea A. Tratat de cercetare științifică în educație fizică și sport. Editura Discobolul, București, 2010, pp. 374-378.

9. Epuran M, Vâjială GE. Metodologia cercetării în educaţie fizică şi sport. Editura Fundaţiei România de Mâine, Bucureşti, 2008, pp. 207-216.

10. David D. Metodologia cercetării clinice. Editura Polirom, București, 2006, p. 35.

11. Bodnar DC, Dimova C, Cristache CM et al. Dental management of patient with 
psychiatric disorders. Modern Medicine. 2010;17(10):538-543.

12. Popescu FD, Popescu SM, Burlibașa M. Platinum group metals as contact allergens in oral rehabilitation. Metalurgia International. 2010;15:12-18.

13. Mihai $A$, Chifiriuc CM, Lazăr V et al. Microbial biofilms in dental medicine in reference to implanto-prostethic rehabilitation. Rev Chir Oro-maxilo-fac Implantol. 2008;1(1):9-13.

14. Ionescu CA, Popovici LR, Mocuța D et al. The quality of human life from the perspective of sustainable development. Metalurgia International. 2009;14:41-43.

15. Eftimie-Totu E, Cristache CM, Isildak S et al. Preliminary studies on citotoxicity and genotoxicity assesment of the PMMA TiO2 nanocompozites for stereolithographic complete dentures manufacturing. Revista de Chimie. 2018;69(5):1160-1165.

16. Mocuța D, Popovici IA, Burlibașa L et al. Impact of the living conditions on population health. Metalurgia International. 2009;14:17-19.

17. Jamous S, Burlibașa L. New insights in molecular analysis of gene regulation - an epigenetic overview. Letters in Applied Nanobioscience. 2018;7(1-2):511-522.

18. Burlibașa M, Muntianu L, Tănase $G$ et al. Study on microbial contamination of biomaterials in medical practice. Metalurgia International. 2010;15(2):163-166.

19. Tănase G, Burlibașa M, Muntianu L et al. Testing the antibacterial potential of biomaterials in medical practice. Metalurgia International. 2010;15(2):160-162.
20. Burlibașa M, Tănase G, Muntianu L et al. Quality of life, a multidisciplinary concept with economic and social impacts in medical practice. Metalurgia International. 2010;15(4):88-90.

21. Burlibașa M, Cernușcă-Mițariu M, Burcea $\mathrm{CC}$ et al. Halogen compounds - theoretical, physiological and practical aspects regarding the decontamination, disinfection and sterilisation of instruments and biomaterials in dental medicine practice. Metalurgia International. 2012;18(3):54-57.

22. Burlibașa $M$, Cernușcă-Mițariu $M$, Cernușcă-Mițariu $S$ et al. Theoretical and practical aspects related to biomaterials decontamination in dental medicine (with reference to dental prosthetics). Metalurgia International. 2013;18(4):261-267.

23. Burlibasa L, Domnariu C. Epigenetic landscape of human diseases. Acta Medica Transilvanica. 2018;23(2):33-37.

24. Cristache CM, Burlibașa M, Cristache $G$ et al. Zirconia and its biomedical applications Metalurgia International. 2011;16(7):18-23.

25. Smeets R, Henningsen A, Jung $O$ et al. Definition, etiology, prevention and treatment of peri-implantitis - a review. Head Face Med. 2014;10:34.

26. Schwarz F, Derks J, Monje A, Wang HL. Peri-implantitis. J Periodontol. 2018;89(Suppl 1):S267-S290.

27. Berglundh T, Armitage G, Araujo MG, Avila-Ortiz G, Blanco J, Camargo PM et al. Peri-implant diseases and conditions: Consensus report of workgroup 4 of the 2017 World Workshop on the Classification of Periodontal and Peri-Implant Diseases and Conditions. J Periodontol. 2018 Jun;89 Suppl 1:S313-S8.

28. Monje A, Insua A, Wang HL. Understanding Peri-Implantitis as a Plaque-Associated and Site-Specific Entity: On the Local Predisposing Factors. J Clin Med. 2019;8(2):279.

29. Jepsen S, Berglundh T, Genco R et al. Primary prevention of peri-implantitis: managing peri-implant mucositis. J Clin Periodontol. 2015;42 Suppl 16:S152-S157.

30. Stacchi C, Berton F, Perinetti G et al. Risk Factors for Peri-Implantitis: Effect of History of Periodontal Disease and Smoking Habits. A Systematic Review and Meta-Analysis. J Oral Maxillofac Res. 2016;7(3):e3.

31. Zandim-Barcelos DL, Carvalho GG, Sapata VM et al. Implant-based factor as possible risk for peri-implantitis. Braz Oral Res. 2019;33(suppl 1):e067.

32. Ahn DH, Kim HJ, Joo JY, Lee JY. Prevalence and risk factors of peri-implant mucositis and peri-implantitis after at least 7 years of loading. $J$ Periodontal Implant Sci. 2019;49(6):397-405.

33. Rösing CK, Fiorini T, Haas AN et al. The impact of maintenance on peri-implant health. Braz Oral Res. 2019;33(suppl 1):e074.

34. Wang WC, Lagoudis M, Yeh CW, Paranhos KS. Management of peri-implantitis - A contemporary synopsis. Singapore Dent J. 2017;38:8-16. 